\title{
Contrapunteo CLACSO y G-20
}

$\Omega$ res años después de haberse realizado en Medellín, con una asistencia inimaginable de veinte mil personas, el Consejo Latinoamericano y Caribeño de Ciencias Sociales, CLACSO, realizó su octava asamblea en la ciudad de Buenos Aires.

Apenas con unos días de diferencia la Ciudad de Buenos Aires fue epicentro de dos eventos que se repelen integral y globalmente, y ello obedece, a manera de síntesis, a que ambos se encuentran en las antípodas frente al fenómeno globo-colonizador del capitalismo, el mercado, el patriarcalismo y la xenofobia.

Entre el 19 y 23 de noviembre bajo la convocatoria de la CLACSO se realizó la 8. ${ }^{a}$ Conferencia Latinoamericana y Caribeña de Ciencias Sociales, que se convirtió en espacio polifónico y plural, multidiverso y pluricultural, el mayor quizás, de formación del pensamiento crítico planetario.

Espacio deliberativo de organizaciones sociales, de universidades y nuevas ciudadanías, expresiones todas emancipatorias al capitalismo en las que se debatieron políticas públicas frente a la igualdad que proponen estrategias de inclusión con un enfoque de derechos humanos; de idéntica manera abanderados en torno a las epistemologías del sur, se puso en evidencia las carencias del pensamiento único hegemónico occidental y se presentaron saberes, prácticas y conocimientos construidos desde paradigmas emergentes, sentipensantes y decoloniales, que demuestran la diferencia semántica y metodológica entre las ciencias de la vida y las ciencias del desarrollo, adscritas a un pensamiento de tradición que ha provocado las dimensiones colosales del cambio climático y la crisis civilizatoria que padece el planeta.

La alegría, la fiesta y los libros fueron el marco de una multitud que se movía de un lado a otro en busca de interrogantes que se develaban o sembraban en cerca de 1000 paneles y 7000 ponencias que se realizaron durante la Conferencia, con un horizonte policromático de ejes temáticos que versaron sobre bienes comunes: estudios sobre la democracia en marcos de desigualdad; la colonialidad en cuerpo de mujer; 
el derecho a la memoria; la educación pública y su crisis planetaria; la teología de la liberación y los 50 años de la Conferencia de obispos de la CELAM en Medellín; la política y el arte para soñar el futuro; el Big data y el algoritmo como arma electoral...

Como colofón de la Conferencia, las discusiones hicieron parte del Foro Mundial de Pensamiento Crítico, las luchas por la igualdad, la justicia social y la democracia en un mundo turbulento, en el que como lo expresa Pablo Gentili, secretario ejecutivo adjunto y coordinador académico de CLACSO, «no nos reunimos para cuestionar lo que se va a discutir en el G-20, sino para tratar de recordarles muy humildemente a quienes nos representen que hay soluciones a muchísimos temas que ni siquiera nuestros líderes mundiales están queriendo discutir».

Renglón seguido a la fiesta Bonaerense de CLACSO, se realizó en la capital argentina la reunión del grupo G-20 compuesto por la Unión Europea y diecinueve gobiernos más, Alemania, Arabia Saudita, Argentina, Australia, Brasil, Canadá, China, Corea del Sur, Estados Unidos, Francia, India, Indonesia, Italia, Japón, México, Reino Unido, Rusia, Sudáfrica y Turquía, concentra el $85 \%$ del producto interno global, el $60 \%$ de la población mundial, el $75 \%$ del comercio planetario, el $80 \%$ de los inversionistas globales, bajo la égida del Fondo Monetario Internacional y el Banco Mundial.

Aunque el despliegue mediático internacional fue colosal, La Cumbre, si pasara a la historia, sería recordada por las decisiones tomadas para resolver los problemas estratégicos de la humanidad - cosa que no sucedió en modo alguno-, más bien aparecerá como una reunión anodina en que aspectos coyunturales como el asesinato de Estado del periodista saudí Jamal Khashoggi, en la embajada de los Emiratos Árabes en Turquía, fue resuelto con un sepulcral silencio estratégico como condescendencia al emir saudí; la esperada reunión entre Donald Trump y Vladimir Putin, que había sigo programada para resolver «la seguridad estratégica, el desarme y los conflictos regionales», fue suspendida un día antes; mientras se esperaba un acto de responsabilidad ambiental y civilizatoria frente al cambio climático y el Acuerdo de París, pasó de soslayo, con un papel «protagónico», mejor histriónico, de Jair Bolsonaro, presidente electo de Brasil, quien se resistió a firmar documento alguno que pueda alejarle de los Estados Unidos, que en 2017 se retiró del Acuerdo de París. El tema de migraciones, que estremece los cimientos de democracias liberales, en tanto viene exacerbando y sacando a flote las fibras autoritarios y neofascistas pasó por alto. $Y$ entre tanto China y Estados Unidos despreciaron la Cumbre como escenario para encausar la guerra comercial que les enfrenta. Una Cumbre del G-20 extremadamente costosa para unos resultados tan pobres.

Los mayores esfuerzos económicos para la realización de la Cumbre se concentraron en financiar maniobras y estrategias de seguridad calificadas como descomunales por los más diversos analistas internacionales, que produjo el desalo y confinamiento de los pobladores y visitantes habituales de Buenos Aires - Centro, garantizadas con la presencia permanente de veintidós mil efectivos de la Policía Federal Argentina, y un número compartimentado de agentes de seguridad internacional, que con vallas, tanquetas y demás impidieron la movilización ciudadana. Igualmente, el espacio aéreo fue cerrado durante los tres días de la cumbre como el acceso a la ciudad por los embarcaderos del Río de la Plata. 
Así, mientras el Congreso de CLACSO fue una fiesta pluricultural florida, una babel de acentos latino-caribeños de integración entre los pueblos, el G-20 simuló un operativo de guerra urbana: Buenos Aires fue el laboratorio de cooperación de la inteligencia militar y policial frente a futuros conflictos transnacionales como los que se evidencian con las movilizaciones de los chalecos amarillos en Francia y las marchas de inmigrantes centroamericanos hacia los Estados Unidos de Trump.

Ninguna de las iniciativas construidas por los movimientos sociales y las universidades y centros de pensamiento construidas y discutidas por CLACSO 2018 fueron ni discutidas ni tenidas en cuenta por la Cumbre del G-20. Ello pone de presente, como lo expone el intelectual portugués Boaventura de Sousa Santos, en la sesión inaugural del eje temático de las Universidades Populares de los Movimientos Sociales, que la dificultad y los retos no están en explicarle a los más pobres cómo funciona la desigualdad, sino que radica en cómo explicar al $1 \%$ de los más ricos del mundo, protegidos por las políticas monetarias del G-20, qué se entiende por inequidad, injusticia y barbarie.
Me animo a concluir con una puerta abierta en cuya manija de nuevo está la mano pedagógica de Boaventura:

A la luz de las epistemologías del Sur, los crímenes cometidos por el capital financiero global serán uno de los principales crímenes de lesa humanidad del futuro. Junto con ellos y articulados con ellos estarán los crímenes ambientales. En el año en que celebramos los setenta años de la Declaración Universal de Derechos Humanos, recomiendo que comencemos a pensar en la revisión de su redacción (y en un modo totalmente nuevo de participación en tal redacción) para dar cuenta de la nueva criminalidad que en los próximos setenta años continuará impidiendo a la humanidad ser plenamente humana.

José Miguel Sánchez Giraldo

Educador Popular

Corporación Universitaria Remington Diciembre de 2018 